\title{
ANAESTHESIA IN CANADA 1847-1967: II. THE DEVELOPMENT OF ANAESTHESIA IN CANADA
}

\author{
HAROLD R. GRIFFITH, M.D., C.M., F.R.C.P. (c), HON. F.F.A.R.C.S. ${ }^{\circ}$
}

\begin{abstract}
AnAesthesiology as a special branch of medicine hardly existed in Canada-or anywhere else-until the dawn of the twentieth century. It was generally considered that any doctor was competent to administer chloroform or ether, and probably more anaesthetics were given in people's homes than in all the hospitals. Rough and ready kitchen table surgery was the rule for tonsil operations, incising abscesses, reducing fractures, and of course for the vast majority of obstetrical deliveries. And even in the hospitals surgery was often performed with far less preparation than we think necessary today. I remember my father, who was a general practitioner in Montreal, telling about how one cold winter day in the early $1890^{\prime}$ 's he bundled a patient with a strangulated hernia into his sleigh, drove him to the Hôtel-Dieu, where Sir William Hingston, with great kindness but little ceremony, took some instruments from a plush-lined box, and after my father had dropped some chloroform on a handkerchief held over the patient's face, proceeded to repair the hernia. Then they lifted the patient back into the sleigh and drove him home. All surgery was not so informal, but certainly anaesthesia was not very well organized or very well done.
\end{abstract}

\section{The Evolution of Hospital Departments}

Sixty years ago the administration of anaesthetics was mainly an occasional duty for general practitioners who might or might not be regular members of the hospital staff. By the end of World War I the pattern had been fairly widely established in the larger hospitals of appointing one or two doctors whose main duty was to administer anaesthetics. It is difficult to decide who should have the credit for establishing the first organized department of anaesthesia in a Canadian hospital, but there is no doubt that the real pioneers are four men who, working quite independently, about 1907 became the first full-time Canadian anaesthetists. These were: Samuel Johnston (1869-1947) at the Toronto General Hospital, William Webster (1865-1936) at the Winnipeg General Hospital, Charles LaRoque (1881-1932) at the Hôtel-Dieu de Montréal, and William B. Nagle (1880-1918) at the Royal Victoria Hospital in Montreal.

Samuel Johnston was a friendly man, gregarious, opinionated, forceful, and dedicated. He became a leader, and was the inspiration for a whole group of younger doctors who set up practice in Toronto after World War I, and made that city a centre for the newly developing specialty-Hanley, Shields, Brown, Robson, Hargrave, Heard, and many others. The staff anaesthetists at all of the major general hospitals in Toronto always worked on a private practice basis;

-Emeritus Professor of Anaesthesia, McGill University, Montreal. 
that is, they gave free service to public ward patients and made their living from fees which they billed directly to private patients. However, in Montreal, Winnipeg, Edmonton, Vancouver, Halifax, and some other cities it became customary for anaesthetists to work as hospital employees, usually at quite meagre salaries. Apart altogether from ethical considerations, this kind of practice had a very deleterious effect on the development of good anaesthesia, because there was very little inducement for bright young doctors to go into this special field. Hospital administrators liked the plan because their hospitals were always financially hard pressed, and they saw an opportunity to make anaesthesia profitable by paying low salaries, and charging fairly good fees to the patients. Surgeons in those days were largely indifferent to the quality of anaesthesia that was provided, and many of them were jealous of their prerogatives of omnipotence and omniscience. Some English hospitals in Montreal began to employ nurses to give anaesthetics, nominally under the direction of doctors, but this practice never became either legal or widely adopted in Canada. But during all the period between the two world wars, and indeed right up until twenty years ago, a battle went on in which anaesthetists were fighting for an improved status and for the right to be recognized as on an equal basis with other specialists. Fortunately for anaesthesia, there were some stalwart leaders in those days. In addition to the Toronto group, there were Wesley Bourne and Romeo Rochette in Montreal, Beverley Leech in Regina, and others. The battles sometimes became bitter, but eventually all along the line the hospitals consented, and departments of anaesthesia were set up in a form which has become almost universally accepted, and which are recognized as indispensable attributes of a good hospital. In recent years, it has become customary for the anaesthetists on a hospital staff to be associated together in some form of group practice on a fee for service basis, and sharing the work in a mutually agreeable fashion. There is no doubt that partnerships of this kind, which vary in size from two to thirty or more doctors, have made it possible to provide better anaesthetic service to all hospital patients, regardless of their economic status, and have given the anaesthetists an opportunity to spread their particular skills into such areas as intensive care and respiratory and cardiac units, and into the problems of emergency resuscitation and inhalation therapy. Moreover, group practice has made it possible to provide twenty-four-hour service without the danger of any one individual's sinking into hopeless exhaustion-a fate all too common in the old days of the individual anaesthetist.

One of the first and strongest examples of co-operating anaesthetists serving the needs of a large hospital was the group led by Beverley Leech, established in 1929 at the Regina General Hospital. Leech, with Mel Bowering and other strong associates, demonstrated how anaesthesiology could be practised ethically, effectively, and successfully. In Western Canada he was almost alone in this type of practice until, in 1950, Digby Leigh led a strong group of young anaesthetists into Vancouver to set up at the Vancouver General Hospital the department which has grown to be the largest in Canada and is still flourishing under the leadership of Horace Graves. In Toronto, for many years, the staff anaesthetists worked as individual doctors, often competing for private patients with one another and with general practitioners. It was really only after World War II 
that the movement toward co-operative groups got under way. Now it is almost universal.

It may sound as if I am putting too much emphasis on these aspects of the development of anaesthesiology in Canada, but I do so purposely because I firmly believe that co-operation in our economic and professional improvement has been the most potent factor in bringing anaesthesia out of the doldrums into which it had fallen just a few years after the exciting events associated with its origin. And of course it was not only anaesthetists who benefited from co-operation and organization, but primarily our millions of patients, who now receive better, safer, and less terrifying anaesthesia than could ever have been imagined fifty years ago.

\section{The Struggle for Recognition and Improved Status}

The original Canadian Society of Anaesthetists was founded by a small but enthusiastic group in 1920. Dr. Samuel Johnston was elected the first president, and Dr. Wesley Bourne the first secretary. Dr. Charles LaRoque succeeded Johnston in the presidency, and then came Dr. William Webster. How fortunate we were in Canada to have these four great men to lead us into the era of modern anaesthesiology. I feel I must digress from my story for a moment to say a word about each of them.

Samuel Johnston, born in Ontario in 1868, graduated from Trinity College of the University of Toronto in 1901, then served as an intern at the Toronto General Hospital, and here he stayed throughout his professional career. The intern of those days was a general handyman, the administration of anaesthetics being one of his many duties. Johnston became interested in what was then a neglected art, and soon became so adept at dropping chloroform and ether that surgeons began to ask for him to look after their cases. Like everyone practising anaesthesia in those days, Johnston was completely self-taught. After his internship he occupied his spare time with general medical practice, but his great interest was always anaesthesia. By 1907 his record was so impressive that the authorities named him chief of a newly created Department of Anaesthesia at the Toronto General Hospital, and Lecturer in Anaesthesia at the University. Sam Johnston was a natural leader, friendly, sociable, a famous raconteur, and beloved by his younger associates. Tom Hanley, Easson Brown, Harry Shields, Stanley Campbell, and Rice Meredith were among those who worked with him, and who later became prominent in Canadian anaesthesia. Johnston travelled to other centres in Britain and America to keep abreast of new developments, and read papers at medical meetings, and he was a natural choice for the first presidency of the Canadian Society of Anaesthetists. In 1935 he retired from his hospital and university appointments, to be succeeded by Harry Shields. To the end of his long life, in 1947, Sam Johnston was affectionately regarded as the dean of anaesthesia in Canada.

William Webster, of Winnipeg, was another stimulating leader who did much to promote the development of our specialty. He was born in England in 1865, came to Winnipeg as a school teacher in 1888 , and then went in for medicine. He graduated from the new University of Manitoba in 1895, and became so 
interested in anaesthesia that he was appointed anaesthetist at the Winnipeg General Hospital and Lecturer at the medical school in 1905. He served with distinction throughout World War I as commanding officer of No. 4 Canadian Field Ambulance, and he was one of the earliest automobile and motorboat enthusiasts in Manitoba. In 1936 he was killed in a fire on his motor boat on the Red River. In 1924. Webster published a volume, The Science and Art of Anaesthesia, which, although it is somewhat outdated, remains to this day the only general textbook of anaesthesia written by a Canadian.

I can speak of Charles LaRoque (1881-1932) with more personal knowledge because I had the privilege of knowing and working with him. In 1906, LaRoque was appointed the first anaesthetist to the historic Hôtel-Dieu de Montréal, Jeanne Mance's hospital, founded with the city in 1642 . His name is recalled by a plaque in the operating suite of the modern hospital with these words, "Pour honorer la mémoire de Charles LaRoque, médecin de l'Hôtel-Dieu, et rappeler sa maitrise dans la science et l'art d'anesthésier. Par ses collègues de la International Anaesthesia Research Society." So well had Charlie done his work, and so widely had he spread the fame of Canadian anaesthesia, that after his untimely death in 1932, his American friends thought it fitting to come to Montreal to pay him this tribute. LaRoque was one of the first to emphasize the importance of the friendly co-operation between French- and English-speaking Canadian anaesthetists which has given us such joy and such strength in all the ensuing years. LaRoque's work at his historic hospital has been continued in this same fine spirit by Larose, Rochette, Longtin, Laporte, and many others.

And now a word about Wesley Bourne (1886-1965) or perhaps more than just a word, because I am prejudiced. If I were called upon to name the greatest of Canadian anaesthetists, I would have to give to him this accolade. Bourne was born in Barbados, graduated from McGill in 1911, and practised anaesthesia in Montreal all the rest of his life. For a time he worked at the Royal Victoria Hospital with William Nagle, and on Nagle's death in 1918, Bourne was asked to take over the department. But he preferred independent practice to a salaried hospital position, and he worked thereafter mainly at the Western Hospital, the Montreal Maternity, and at St. Mary's Hospital. In 1921 he was appointed Lecturer in Pharmacology at McGill University, and continued to work there in his spare time until he was appointed McGill's first Professor of Anaesthesia in 1945. In my opinion, Wesley Bourne's greatest contributions to the progress of anaesthesiology were his insistence upon the importance of an understanding of basic sciences for good clinical practice, and his stimulating influence as a teacher. $\mathrm{He}$ spoke and wrote lucidly and with great erudition, and soon he was recognized throughout the world. In 1932 he was named vice-president of the Section of Anaesthesia of the British Medical Association, and in 1935 he was awarded the first Hickman Medal by the Royal Society of Medicine. In 1942 he was elected president of the American Society of Anesthesiologists, the only foreigner ever to be so honoured, and in 1952-53 he served for 18 months as visiting professor of anaesthesia at the University of Paris, under the auspices of the World Health Organization.

It is fortunate, therefore, that we had Wesley Bourne and his three colleagues, 
Johnston, Webster, and LaRoque, and other enthusiastic pioneers as the organizers and principal officers of our first Canadian Society of Anaesthetists. Bourne designed the well-known crest of the Society, which shows the Greek god Hypnos pouring the poppy juice from his horn, and he chose for its motto the Greek words "Katheudontas parateroumen" which mean "We watch closely those who sleep." The Society flourished for a few years, but by 1928 the members were persuaded to become a Section of the Canadian Medical Association, and the federal charter was surrendered.

In the years which followed it seemed increasingly clear to some of us that we were lost in the anonymity of the larger Association, and that the special interests of anaesthetists could be looked after better in an organization of our own. In 1930 the Montreal Society of Anaesthetists was formed with Charles LaRoque the first president, and it soon became a real force in promoting good feeling and better scientific knowledge among the French- and English-speaking anaesthetists of the province of Quebec. Efforts were made during the early years of the war to revive the defunct Canadian Society, but the response was only half-hearted, and nothing was accomplished until 1943 when the Montreal Society of Anaesthetists went ahead independently and transformed itself legally into the Canadian Anaesthetists' Society, with Divisions in each province. And so, here in Montreal, was born our present Society, which is now twenty-four years old, and in a very healthy condition. I had the honour of serving for three years as the first president, and Digby Leigh was the first secretary-treasurer. Kenneth Heard of Toronto was the first vice-president, and succeeded me in the presidency. Rod Gordon took over as secretary-treasurer in 1946, the headquarters was moved to Toronto, and the strength and growth of the Society are testimony to the leadership which he has provided for many years. Since this paper is a birds-eye history of Canadian anaesthesia and not just of the Canadian Anaesthetists' Society, I can't take time to tell the whole story of its accomplishments, but I do want to say that the annals of the Society are richly adorned with the names of many men and women who have contributed unselfishly and whole-heartedly-Shields, Cousineau, Leech, Hudon, Watt, Noble, Allard, Lunny, O’Donnell, Graves, Morton, Gain, Longtin, Gilbert, Meredith, McAlpine, Campbell (two of them), and ever so many others.

Coinciding with the growth of the Canadian Anaesthetists' Society there has been increased prestige for the specialty of anaesthesiology. About 25 years ago the Royal College of Physicians and Surgeons of Canada began to issue specialist certification, and today Anaesthesia is the largest specialty group in the College, other than Internal Medicine and General Surgery. In 1951 the Royal College agreed to give fellowship status to anaesthetists, and the question arose as to whether we should be classified as physicians or as surgeons. It was decided, rightly I believe, that we are primarily physicians, and so today nearly 200 Canadian anaesthetists have the right to add F.R.C.P.(C) to their names.

\section{The Introduction of New Agents and Methods}

The contributions of Canadians toward the introduction of new agents and improved methods into anaesthesiology have been numerous and important. 
Very early in the modern era many Canadian anaesthetists recognized the importance of a free airway, and efforts were made to improve the means by which this could be assured. As early as 1913 William Nagle of Montreal reported in the British Medical Journal his experience in 300 intratracheal ether administrations, and I remember watching Wesley Bourne, in 1914, intubate a patient in a critical situation, much to the amazement of incredulous surgeons. Charles $\mathbf{H}$. Robson and Harry Shields became adept at intubation during World War I when they were anaesthetists in Canadian military hospitals, and by the early 1920's intratracheal ether-air insufflation was a fairly common practice in hospitals in various parts of Canada. However, it was the introduction of endotracheal inhalation anaesthesia, using large catheters with to-and-fro breathing, which made possible the use of the gases, and which really revolutionized anaesthesia. Ralph Hargrave at Toronto Western Hospital and Charles Stewart at the Montreal General Hospital were pioneers at intubating under nitrous oxide. In 1928 Hargrave wrote about the use of large-bore wire-woven catheters, and the same year I read a paper on "Intratracheal Ethylene-Oxygen Anaesthesia." Nowadays it is hard to believe how strange these papers sounded when they were first delivered, because at that time probably not ten per cent of those administering anaesthesia had ever intubated a patient. C. H. Robson at the Hospital for Sick Children, Toronto, was perhaps the most skilful of the early intubators. Many a time I have been amazed to watch him put a tube into a small child's trachea by dextrous use of his fingers and without any laryngoscope. Indeed, Robson's contributions to the advancement of anaesthesiology have been many, and should be recognized. He was perhaps the first anaesthetist really to specialize in work with children, and he made Canada famous in this field. He rightly deserves the title of "Father of Paediatric Anaesthesia."

In the years just after World War I, Wesley Bourne in Montreal and William Easson Brown in Toronto were practically the only Canadian anaesthetists who were dabbling also in pharmacology. In 1923, Brown, working in Prof. Velyien Henderson's laboratory, conducted experiments in the use of ethylene, an agent which he believed he was using for the first time. He was quite unaware of the coincidental and more extensive studies of this agent by Luckhardt and his group in Chicago, which were published almost simultaneously. However, some years later, in 1929, the Pharmacology Department of the University of Toronto did proclaim an anaesthetic agent, cyclopropane, for which Henderson, Lucas, and Brown justly received credit. It is perhaps too bad that the Toronto group, either through timidity or indifference, did not go on from there to demonstrate cyclopropane in clinical practice. This was left to Waters and his associates at the University of Wisconsin, and I believe that my use of cyclopropane in Montreal in October 1933 was the first time it was given in an operating room in Canada.

During the 1930's Canadians were taking an active part in the evaluation of new drugs which seemed to be appearing in unprecedented abundance. In 1933, at the University of Alberta, vinyl ether was first used as an anaesthetic, and John Blezard, pioneer Edmonton anaesthetist, who later became the first professor of anaesthesia at the University of Western Ontario, was the first anaesthetist to administer it. Tribromethanol ("Avertin") became very popular in those years, 
and the short-acting barbiturates ("Pentothal," etc.) appeared on the scene. Papers by Wesley Bourne based on laboratory and clinical studies, and often in collaboration with Raginsky, Stehle, Barbour, Melville, or O'Shaughnessy, evaluating these new agents, were published frequently in medical journals throughout the world. Bourne became something of an oracle. By 1948, in introducing a symposium on the basic sciences in anaesthesia he felt it opportune to remind us of the words of another great Canadian, Sir William Osler, who said:

The true student is a citizen of the world. ... The great minds, the great works transcend all limitations of time, of language, and of race, and the scholar can never feel initiated into the company of the elect until he can approach all of life's problems from the cosmopolitan standpoint. . . . The dangers do not come to the strong man in a specialty, but to the weak brother who seeks in it an easier field in which specious garrulity and manual dexterity may take the place of solid knowledge. . . . Next to the danger from small men is the serious risk of the loss of perspective in prolonged and concentrated effort in a narrow field. Against this there is but one safeguard-the cultivation of the sciences upon which the specialty is based. The student specialist may have a wide vision-no student wider-if he gets away from the mechanical side of the art, and keeps in touch with the physiology and pathology on which his art depends. ... He needs the lessons of the laboratory, and wide contact with men in other departments may serve to correct the inevitable tendency to a narrow and perverted vision, in which the life in the ant-hill is mistaken for the world at large.

I suppose that perhaps the introduction of the use of curare into anaesthesiology is the most resounding of Canadian contributions to the development of modern surgery. Recently at the Royal College of Surgeons in London, I was somewhat startled to hear this spoken of as an advance which ranks with Lister's discovery of antisepsis. With my colleague, Enid Johnson MacLeod, presently of Dartmouth, I somewhat fortuitously first administered curare to a patient under anaesthesia, in Montreal, on January 23, 1942, and we published our findings in a short paper which appeared in Anesthesiology (vol. 3: 418-420) in July of that yearalmost exactly a quarter of a century ago. This work resulted in some criticism and considerable skepticism, but nevertheless within a few years it really changed the practice of anaesthesiology, and led to the introduction of all the muscle relaxants, and to many other drugs. Today no one would want to go back to the pre-relaxant days; so I think it right to include curare in anaesthesia among the Canadian achievements.

Since the first use of curare many other Canadians have contributed to the further elucidation of the muscle relaxants, and to our knowledge of new agents such as the tranquillizers, trilene, halothane, and methoxyflurane. Investigative work is being carried on with precision and skill in many of our Canadian hospitals. I can't even list the names of all those present leaders who are responsible for the expansion of research activity. It goes on in laboratories and in operating rooms right across the country, and we now have the advantage of publication in our own splendid Journal. I think, however, that I should mention particularly the work of Fernando Hudon, who for so many years was the stimulating, dynamic, enthusiastic chief of anaesthesia at the Hôtel-Dieu de Québec and at the Univer- 
sité de Laval. With eager interest he seized upon anything new as soon as it appeared in anaesthesia literature, tried it out, quickly sorted out the good from the bad, and added greatly to our knowledge. Hudon was a fine teacher, and he made his hospital the alma mater for a whole generation of brilliant young Canadian anaesthetists-including even my collaborator in this history, my dear friend André Jacques.

\section{The Teaching of Anaesthesia}

When I started to practice, most anaesthetists taught themselves. In a few hospitals in Toronto and Montreal there were apprenticeship-type residencies, but no organized programme until the Royal College became interested, and even after that there was very little interest in specialty teaching of anaesthesia at any Canadian medical school. The need for qualified anaesthetists in the armed services during World War II is what finally convinced medical educators that something more had to be done. In Montreal a short intensive course in anaesthesia for medical officers, in which I had a part together with Wesley Bourne and Digby Leigh, demonstrated what could be accomplished. In many of our present leaders the first spark of interest in anaesthesiology was lighted during those busy weeks in Montreal, and the flame never died out.

In 1945, the governors of McGill decided to establish a Department of Anaesthesia in the Faculty of Medicine and appointed Wesley Bourne the first professor and chairman. The three-year diploma course for graduate teaching was immediately successful, and became the model or the stimulus for similar programmes in other Canadian medical schools. Today in our 14 medical schools, 12 have organized departments of anaesthesia, and the other two are just getting started. The vast majority of hospitals which are approved by the Royal College for graduate training in anaesthesia are affliated in some way with the universities. To those of us who can look back to the disorganized condition of teaching even 25 years ago, this is a startling and very satisfactory change.

Ever since anaesthesia was first considered a specialty, Canadians have been interested in helping to promote progress in other countries. Many doctors come to us from all over the world for training, and we have co-operated in setting up teaching departments in some underdeveloped countries. The University of Toronto sponsors the chair of anaesthesia at the University of Lagos in Nigeria. Our own Shirley Fleming has served there devotedly for a number of years, assisted for periods by Earl Russell, Eric Webb, and other Canadian anaesthetists, and Rod Gordon commutes back and forth to Africa.

Many years ago Dr. Frank McMechan and his wife Laurette founded the International Anesthesia Research Society. They helped our early Canadian Society become established, and it was their dream that some day anaesthesiologists would be united in a world brotherhood for the promotion of better anaesthesia everywhere. Canadians can be proud that they have played a leading part in making this dream almost a reality. Today the World Federation of Societies of Anaesthesiologists is made up of members from 54 countries, and is a powerful force in helping struggling anaesthesiologists in countries where a few years ago 
good anaesthesia was quite unheard of. The second congress of the World Federation was held in Toronto in 1960, its Founder President is a Canadian, and other Canadians are taking an active part in all its deliberations.

More anaesthesiologists are needed here, and in every country. The value of their services is beginning to be appreciated. I think we can face the second century of Canada with confidence, with hope, and with thankfulness for all those whose work and devotion have made possible such progress during the past 120 years. We can all thank God that we are engaged in a vocation which is indispensable, which is fascinating, and which is worth doing well. 